\title{
A clinical study on the tip localization of peripherally inserted central catheter (PICC) guided by intracavitary electrocardiography in newborns: a randomised trial
}

\author{
Li-Bo Zhu", Ling Liu\#, Tie-Song Zhang, Yu-Ting Zheng, Chun-Yan Lu, Kun Lu, Shu-Xian Zhang, \\ Liu-Yan Duan, Mei-Lin Yang
}

Department of Neonatology, Kunming Children's Hospital, Kunming, China

Contributions: (I) Conception and design: LB Zhu, L Liu; (II) Administrative support: LB Zhu, L Liu; (III) Provision of study materials or patients: TS Zhang, YT Zheng, CY Lu, K Lu, SX Zhang, LY Duan, ML Yang; (IV) Collection and assembly of data: TS Zhang, YT Zheng, CY Lu, K Lu, SX Zhang, LY Duan, ML Yang; (V) Data analysis and interpretation: LB Zhu, L Liu; (VI) Manuscript writing: All authors; (VII) Final approval of manuscript: All authors.

"These authors contributed equally to this work.

Correspondence to: Tie-Song Zhang, MD. Department of Neonatology, Kunming Children's Hospital, 288 Qianxing Road, Xishan District, Kunming 650228, China. Email: drzhang_zts1175@163.com.

Background: The present study aimed to investigate the $\mathrm{P}$-wave changes in intracavitary electrocardiography (IC-ECG) during catheterization with a peripherally inserted central catheter (PICC) in order to provide guidance for the accurate localization of the tip of the PICC.

Methods: A total of 106 newborns who needed a PICC were randomly divided into two groups-a study group and a control group-using a random number table, with 53 cases in each group. In the study group, the ECG monitor was connected after the successful puncture and insertion of the PICC into the right sternoclavicular joint, and the position of the catheter tip was determined according to the $\mathrm{P}$-wave changes on the IC-ECG. Localization X-rays were taken at the same time. In the control group, after the successful routine puncture and insertion of the PICC into the location to a predetermined length, localization X-rays were taken. The accuracy, procedure duration, and cost of the two localization methods were evaluated.

Results: The accuracy of the localization in the study group was $92.5 \%$, but the difference was not significant when compared with the control group $(\mathrm{P}>0.05)$. The duration of the procedure in the study group was $5.12 \pm 1.57$ minutes, and the cost was $7.12 \pm 0.56$ yuan, both of which were significantly different when compared with the control group $(\mathrm{P}<0.05)$.

Conclusions: P-wave changes during IC-ECG have high accuracy in determining the location of the tip of the PICC. It is also a simple method and has certain clinical application value.

Trial Registration: Chinese Clinical Trial Registry (number: ChiCTR2100047660).

Keywords: Intra-atrial electrocardiogram; characteristic P wave; peripherally inserted central catheter (PICC); newborn; intensive care unit

Submitted Nov 05, 2020. Accepted for publication Jul 20, 2021.

doi: $10.21037 /$ tp-20-370

View this article at: https://dx.doi.org/10.21037/tp-20-370

\section{Introduction}

The peripherally inserted central catheter (PICC) is an important technology that can be used to ensure a high energy supply for infants with low birth weight and very low birth weight in the neonatal intensive care unit (NICU) (1-4). However, incorrect localization of the tip of the PICC can lead to catheter-related complications. Shallow or ectopic localization makes the procedure more prone to 
failure and can lead to the formation of venous thrombosis and a fibrin sheath. If the catheter is placed too deep, such as in the right atrium or ventricles, it may cause arrhythmia, dysfunction, or erosion of the tricuspid valve, as well as atrial thrombosis and other complications. In newborns, the PICC procedure is carried out under blindness, making it more difficult to ensure that the tip of the catheter is exactly $0.5-1.0 \mathrm{~cm}$ away from the upper cavity (5-7); this increases the likelihood that the catheter will be ectopic.

In recent years, intracavitary electrocardiography (ICECG) has been used more frequently in the field of PICC catheterization in both adults and children to localize the position of the catheter. IC-ECG has been found to be simpler and more economical, convenient, and accurate than the traditional method (8). It is therefore necessary to determine whether IC-ECG can also be used for PICC catheterization in newborns, who have special physiological and structural characteristics. The present study aimed to investigate the $\mathrm{P}$-wave changes in IC-ECG during PICC catheterization in newborns in order to provide guidance for the accurate localization of the tip of the PICC. We present the following article in accordance with the CONSORT reporting checklist (available at https://dx.doi. org/10.21037/tp-20-370).

\section{Methods}

\section{General data}

A total of 106 newborns were enrolled in the study based on the inclusion and exclusion criteria.

Inclusion criteria: (I) newborns who needed PICC catheterization in our NICU between May 2015 and May 2017 and were selected to be catheterized via the vein route of the upper extremity or superficial temporal vein route; (II) newborns who needed parenteral nutrition treatment for 7 days or more; (III) newborns with no arrhythmia in the ECG on the body surface and who had a heart rate of 90-180 bpm; (IV) newborns with no lesions or scars on the local skin; (V) newborns with no fever, bacteremia, or physical activity disorders.

Exclusion criteria: (I) the legal guardian of the newborn refused to participate in the study; (II) newborns with arrhythmias, of various causes, that could affect the monitoring of the $\mathrm{P}$-wave.

The study was conducted in accordance with the Declaration of Helsinki (as revised in 2013). The study was approved by institutional ethics board of Kunming Children's
Hospital (NO.: 2016-03-001-H01) informed consent was taken from the patients' parents or legal guardians.

\section{PICC catheterization methods}

The enrolled patients were randomly divided into two groups-a study group and a control group—of 53 patients each using a random number table. The sample size was calculated using PASS software.

\section{The study group (IC-ECG characteristic P-wave localization group)}

(I) This was connected with the bedside ECG monitor and set at lead II. Four electrodes were attached to the bilateral skin under the clavicle and abdomen, respectively. The arm on the puncture side was extended at $90^{\circ}$, and the distance between the puncture point and inner side of the right sternoclavicular joint $+0.5-1.0 \mathrm{~cm}$ was measured to determine the catheter length during ECG positioning.

(II) Under the maximum aseptic barrier, the PICC puncture and catheterization were performed using conventional methods. When the catheter was successfully inserted to the predicted length, the first third of the no. 7 scalp needle was inserted into the heparin cap at the end of the catheter and the ECG was clamped to the middle of the steel needle to observe the $\mathrm{P}$-wave changes on the ECG (see Figure S1).

(III) Using a $20-\mathrm{mL}$ syringe, $0.9 \%$ sodium chloride solution was connected to a scalp needle. At the same time, the ECG module was adjusted to the PICC mode, and the sodium chloride solution was slowly injected. Regular mechanical waves were visible, indicating that the sodium chloride solution had an effect on the ECG.

(IV) The position of the tip of the PICC was further determined, and the $\mathrm{P}$-wave was observed when delivering the catheter. When the amplitude of the $\mathrm{P}$-wave was as high as that of the $\mathrm{R}$-wave, the insertion of the pipe was stopped and $0.5-1.0 \mathrm{~cm}$ was withdrawn. The high spike then dropped, and the ratio of the $\mathrm{P}$-wave amplitude to the $\mathrm{R}$-wave amplitude was approximately $60-80 \%$, which indicated the localizing position.

(V) The catheter was fixed, the length of the catheter was recorded, and X-ray localization was performed. 


\section{Control group}

(I) The length of the inserted catheter was measured before the PICC catheterization procedure, and the prediction method was the same as that of the study group.

(II) After the catheter was successfully inserted to the predicted length by routine PICC puncture, the patient was sent to the Radiology Department for an X-ray, and the location of the catheter tip was determined.

(III) The patient was then sent back to the ward, and the catheter position was re-adjusted according to the $\mathrm{X}$-ray results (9).

(IV) The right arm lead was attached to the scalp needle. Type of PICC: disposable central intravenous catheter set, brand: UNI-PICC, size: $1.9 \mathrm{Fr} \times 40 \mathrm{~cm}$.

\section{Assessment of the position of the catheter tip}

The chest radiographs revealed that the tip of the catheter was located in the 5 th -7 th thoracic vertebrae, which indicated that the tip of the PICC should be located in the lower third of the superior vena cava, or the junction of the superior vena cava and right atrium, which is in accordance with the recommendations of the American Society of Intravenous Nurses, 2011. All chest radiographs were interpreted by the same radiographer. If the tip of the catheter was located in the axillary vein, subclavian vein, or internal jugular vein, it was considered to be catheter heterotopia $(10,11)$.

\section{Main outcome indicators}

The main outcome indicators were the accuracy, procedure duration, and cost of each catheter localization method.

\section{Statistical analysis}

SPSS 20.0 statistical software was used for data processing and analysis. Measurement data were expressed as mean \pm standard deviation, and countable data were expressed as a percentage (\%). A W-test was used for the normality test, an F-test was used for homogeneity of variance, and a $t$-test was used for comparison between two groups. A nonparametric test was used to compare the mean values of various samples that did not obey the normal distribution or obeyed the normal distribution but had different variances. $\mathrm{A} \chi^{2}$ test was used for countable data. $\mathrm{P}<0.05$ was considered statistically significant.

\section{Results}

\section{General data}

A total of 106 newborns (58 male and 48 female) who needed PICC catheterization were enrolled in the present study (see Figure 1). Their gestational ages ranged between 28 and 36 weeks, and their birth weights ranged between 1,500 and 2,000 g. The duration of their hospital stays ranged between 14 and 60 days. The details are given in Table 1.

\section{IC-ECG changes}

The P-waves on the IC-ECG were observed in the 53 newborns in the study group during catheterization. In 49 cases, the amplitude of the $\mathrm{P}$-wave was $60-80 \%$ that of the $\mathrm{R}$-wave, and the chest $\mathrm{X}$-rays revealed that the tip of the catheter was in the 5 th-7th thoracic vertebrae. The remaining four cases had abnormal $\mathrm{P}$-waves, which included no specific $\mathrm{P}$-wave or the existence of an interference wave, and the chest $\mathrm{X}$-rays revealed that the catheters were ectopic. See Figures 2-5.

\section{Comparison of the accuracy, procedure duration, and cost of each PICC catheterization method}

In the study group, the localization of the PICC was confirmed by X-ray after IC-ECG localization, and the localization accuracy was $100 \%$. However, there was no significant difference in accuracy between the study group and control group $(\mathrm{P}>0.05)$. The duration of the procedure was shorter in the study group than in the control group and the cost was lower in the study group than in the control group, with both differences being statistically significant $(\mathrm{P}<0.05)$. The sensitivity and specificity of the catheter localization through the observation of the $\mathrm{P}$-wave in the IC-ECG in the study group were $100 \%$ and $92.5 \%$, respectively (see Tables 2,3). Regarding complications, pneumothorax was found in five cases and skin lesions in six cases.

\section{Discussion}

The results of the present study revealed that, although the specificity of localization in the study group was $92.5 \%$, 


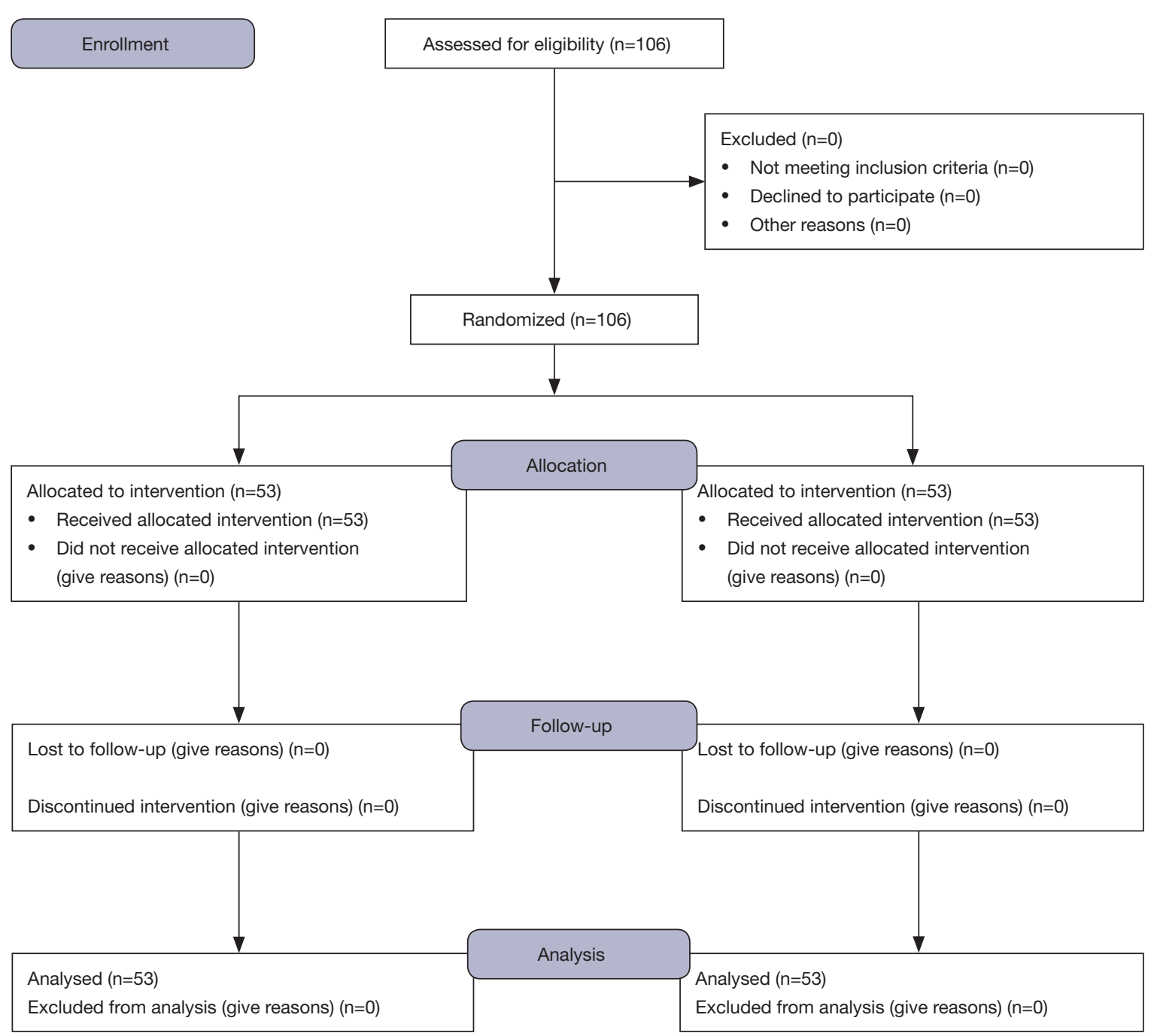

Figure 1 Participant flow diagram.

the difference was of no statistical significance when compared with that in the control group. The duration $(5.12 \pm 1.57$ minutes $)$ and cost $(7.12 \pm 0.56$ yuan $)$ of the method used in the study group, however, were significantly different when compared with the control group. The similarity in localization accuracy between the two groups found in the present study differed from the findings of previous studies, for which there could be several reasons, including the study's limited sample size, the skill level of the operators, and the different cardiovascular status of the patients.

Previous studies regarding the use of IC-ECG in the localization of the tip of the PICC have shown that there is a significant change in the peak of the $\mathrm{P}$-wave during the process of the insertion of the PICC tip from the superior vena cava through the sinoatrial node to the right atrium. This technique aims to convert the atrial ECG to the body surface ECG through the intracardiac connection converter, thereby allowing the changes in the cardiac $\mathrm{P}$-wave to be directly visible under the ECG. When the PICC catheter is ectopic, this is the same as the ECG on the body surface. When the tip of the catheter enters the junction of the superior vena cava and right atrium, the $\mathrm{P}$-wave reaches a peak, and the deeper the tip of the catheter is, the higher the amplitude of the $\mathrm{P}$-wave becomes, sometimes even resulting in two-way and inverted waves (12-15).

In the present study, $0.9 \%$ sodium chloride solution and a scalp needle were used as electrodes. The sodium chloride solution was continuously injected into the right atrium via the PICC in order to detect the P-wave changes on the IC- 
Table 1 The general characteristics

\begin{tabular}{|c|c|c|c|}
\hline Index & Control group & Study group & $\mathrm{P}$ \\
\hline Sex (male/female) & $29 / 24$ & $29 / 24$ & 0.577 \\
\hline Age (days), median (range) & $5.00(3.00,8.50)$ & $4.00(2.00,7.00)$ & 0.213 \\
\hline Weight (kg), median (range) & $2.06(1.80,2.58)$ & $2.16(1.92,2.61)$ & 0.204 \\
\hline Premature infant & $15(28.30)$ & $6(11.32)$ & \\
\hline Abdominal distension & $9(16.98)$ & $11(20.75)$ & \\
\hline Hematochezia & $1(1.89)$ & $3(5.66)$ & \\
\hline Digestive tract malformation & $2(3.77)$ & $1(1.89)$ & \\
\hline PICC placement purpose, n (\%) & & & 0.423 \\
\hline Supplement nutrient solution & $28(52.83)$ & $30(56.60)$ & \\
\hline Medication & $25(47.17)$ & $23(43.40)$ & \\
\hline
\end{tabular}

PICC, peripherally inserted central catheter.

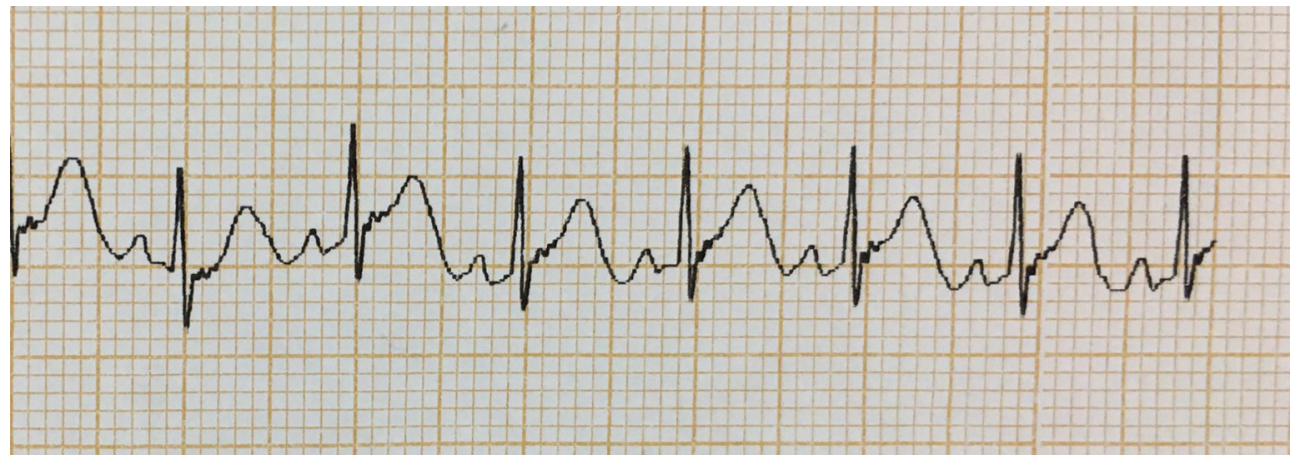

Figure 2 The normal body surface electrocardiogram in newborns before puncture with a peripherally inserted central venous catheter.

ECG. When the tip of PICC reached the right atrium, a characteristic high-peak P-wave, two-way wave, or inverted wave was generated by the IC-ECG. Once the high-peak $\mathrm{P}$-wave of the superior vena cava decreased, the position of the catheter tip was determined based on the ratio of the amplitude of the high-peak $\mathrm{P}$-wave to that of the $\mathrm{R}$-wave (16-18). It was found that, when the catheter was inserted to the predicted length, there was no characteristic change in the P-wave, indicating that the catheter was ectopic. Hence, it was necessary to adjust the body position and re-insert the catheter.

The IC-ECG localization method has the advantages of a shorter duration and lower cost. In addition, the accuracy of IC-ECG in determining the location of the PICC catheter in newborns was better that that of the traditional method. Furthermore, traditional X-rays expose newborns to radiation, which is not desirable, and the IC-ECG can be used where a bedside machine is unavailable; it can also be used as a means of real-time monitoring. IC-ECG is easy to operate, and the position of the catheter can be adjusted at any time during the process, meaning the puncture and localization can be completed in the same procedure $(19,20)$.

In newborns, the heart conduction system is not fully matured, the regulation of excitation is poor, and 


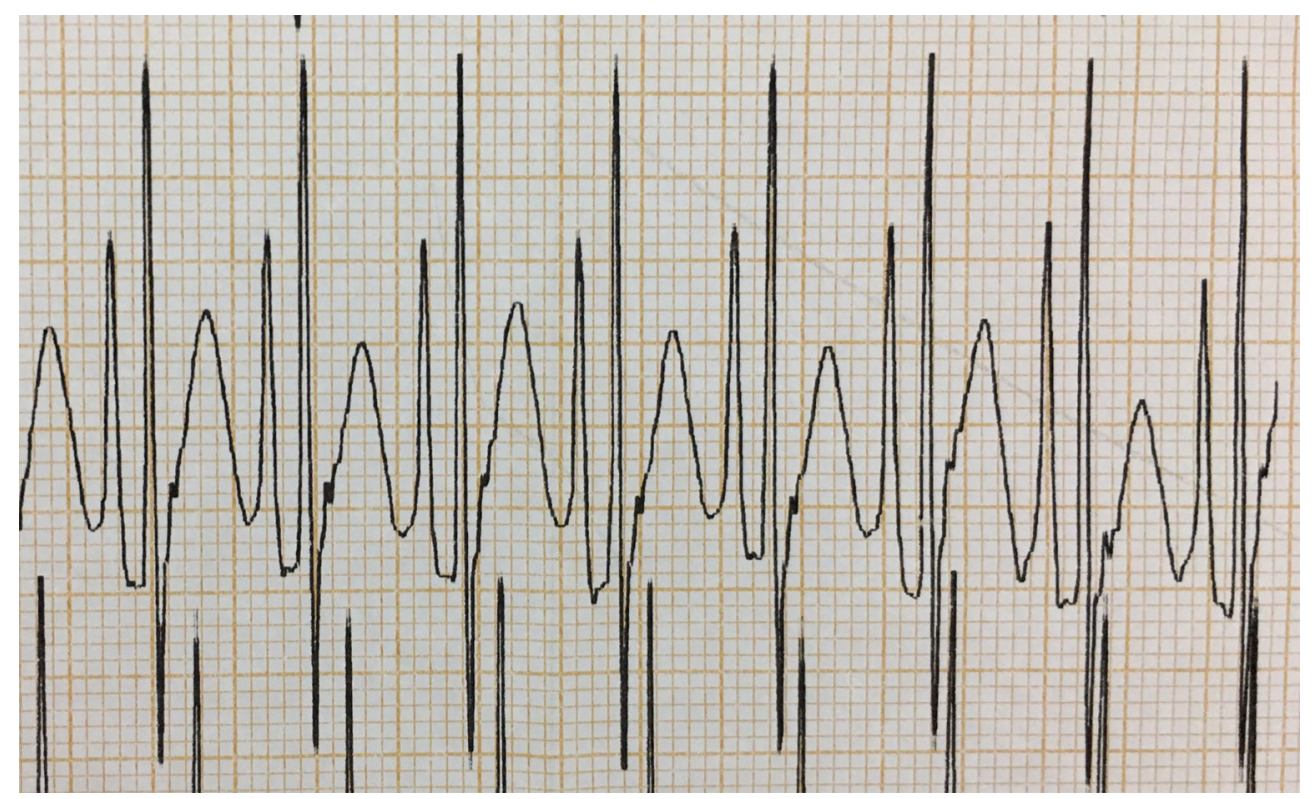

Figure 3 After the successful puncture and insertion of the catheter to a depth of one third of the upper and lower segments of the superior vena cava, the $\mathrm{P}$-wave changes presented with a gradually increasing and sharp shape.

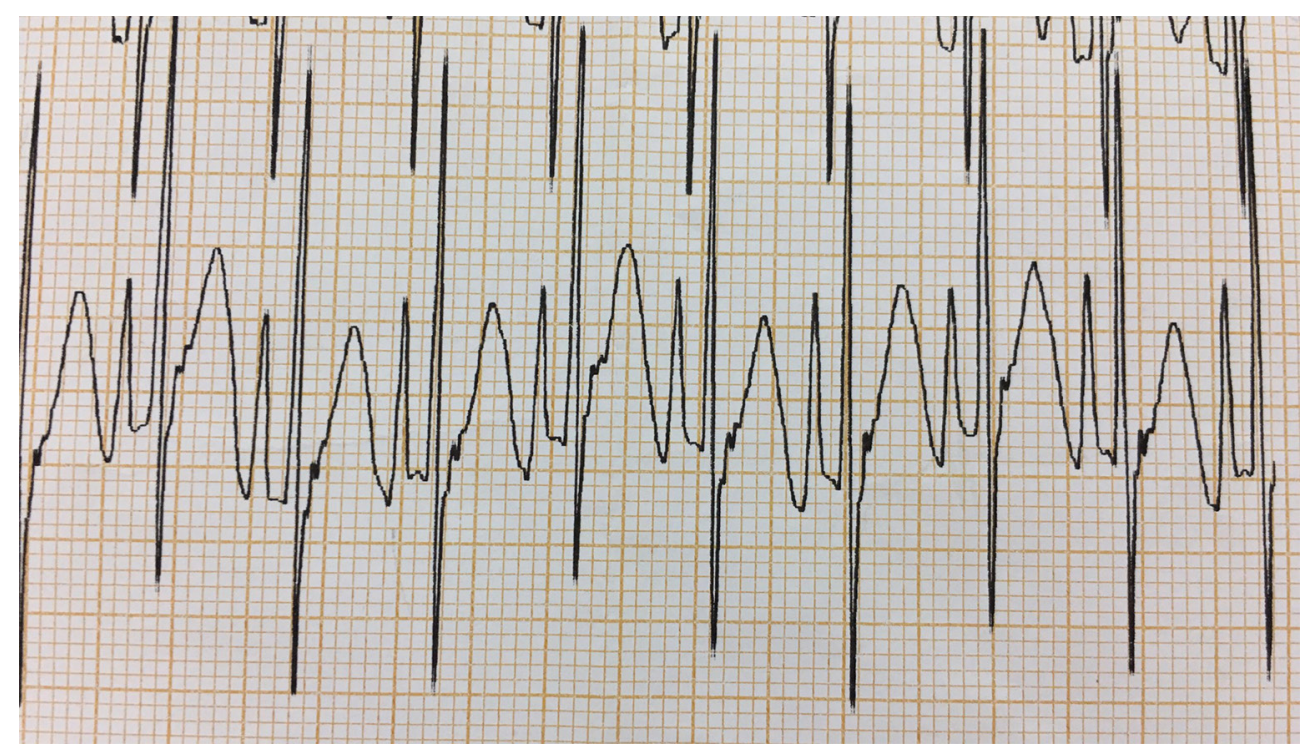

Figure 4 When the catheter was placed in the 5 th-7th thoracic vertebrae, the P-wave turned to a positive position and the amplitude was the same as that of the QRS wave.

the development of the sinoatrial node is imperfect. Intrauterine distress and apnea can lead to the abnormality or disappearance of the $\mathrm{P}$-wave. Therefore, the type of $\mathrm{P}$-wave does not necessarily cause these factors in newborns. Furthermore, newborns, as a special population, do not actively cooperate with procedures and are prone to crying and moving, which can lead to the failure of ECG signal acquisition. In order to collect an accurate ECG waveform without interference, non-nutritive sucking, oral sucrose water, and sedatives can be used to ensure that the newborns remain in a quiet state (9).

In the present study, the newborns in the study group 


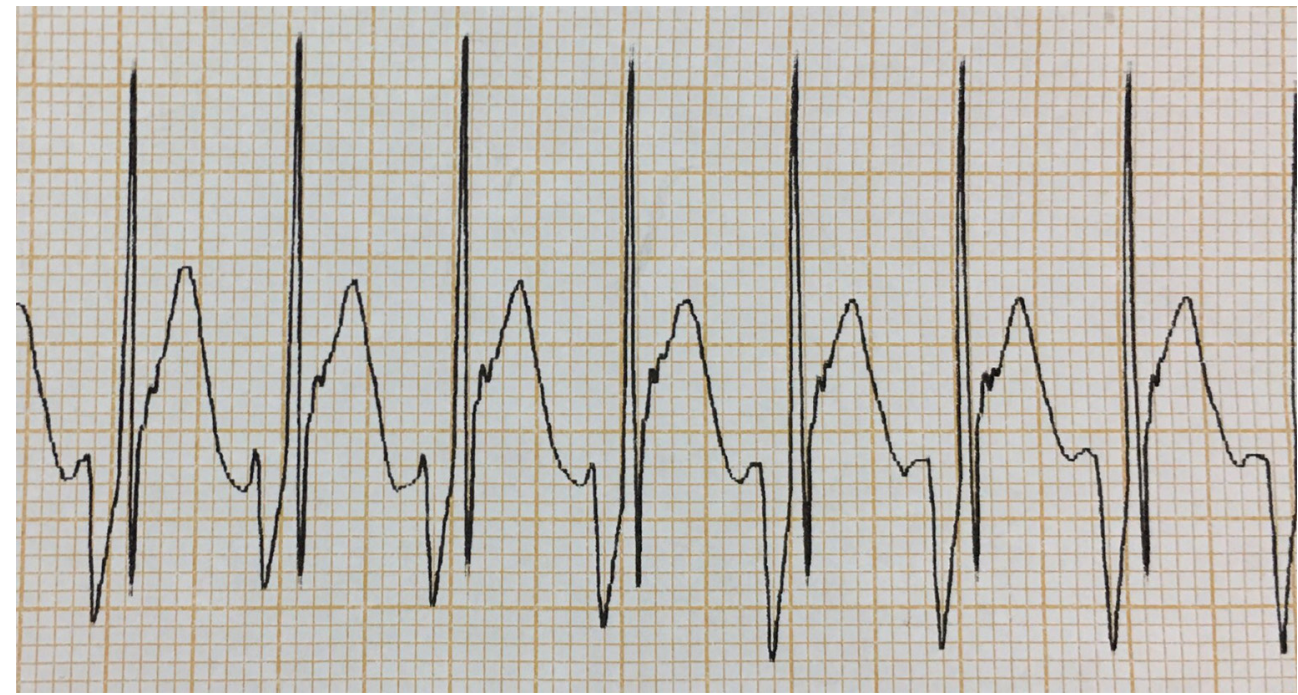

Figure 5 When the catheter was inserted to the position below the 8th thoracic vertebra, the P-wave was inverted.

Table 2 Comparison of the accuracy of localization, duration and cost of the PICC between the two groups

\begin{tabular}{lcccc}
\hline Groups & $\mathrm{N}$ & Accuracy of localization (\%) & Duration of the PICC (min) & Cost of the PICC (yuan) \\
\hline Study group & 53 & 92.5 & $5.12 \pm 1.57$ & $7.12 \pm 0.56$ \\
Control group & 53 & 92.5 & $20.65 \pm 15.12$ & $110.47 \pm 31.17$ \\
$\chi^{2} / t$ & 3.180 & 9.119 & 27.336 \\
$P$ & & 0.128 & $<0.001$ & $<0.001$ \\
\hline
\end{tabular}

PICC, peripherally inserted central catheter.

Table 3 The sensitivity and specificity of the IC-ECG

\begin{tabular}{lccc}
\hline X-ray localization & Specific P-wave & No specific P-wave & Total \\
\hline $5-7$ thoracic vertebrae & 49 & 0 & 49 \\
Catheter heterotopia & 0 & 4 & 4 \\
Total & 49 & 4 & 53 \\
\hline
\end{tabular}

IC-ECG, intracavitary electrocardiography.

had a lower rate of ectopic PICC catheterization, which reduced the cost associated with secondary catheterization and shortened the length of hospital stay. Therefore, the overall treatment costs were lower. In comparison, the cost of the treatment in the control group was higher because of longer hospital stays and the possibility of secondary catheterization.

The present study had some limitations. First, although the study was a randomized controlled trial, there was no blind method, so there was a risk of bias. Second, the study was a single-center clinical study, with a small sample size. As such, further multi-center clinical studies are required.

\section{Conclusions}

The method of observing $\mathrm{P}$-wave changes using ICECG has high accuracy and can be easily performed to determine the position of the PICC. Furthermore, it can monitor the localization of the catheter in real time without increasing the pain of the patient or the cost of treatment, 
and the location of the catheter can be adjusted at any time during the procedure. This may allow for the completion of the PICC puncture and catheter positioning in a single procedure time, ensuring the timeliness of drug application in newborns, reducing the workload of medical staff, and avoiding the repeated exposure of patients to X-ray radiation, which has value for clinical application.

\section{Acknowledgments}

We would like to thank Kim Huggens for his/her help in polishing our paper.

Funding: This study was supported by Kunming Health Science and Technology Talent Training and Technology Center Construction Project: Kunming Technology Center for High Risk Infant Care [No.: 2017-SW(Tech)-13] and Project of Health Research Project of Kunming Health and Health Commission: Research on the application of ultrasound-guided puncture combined with intra-atrial electrocardiogram to locate the tube end in neonatal PICC placement [No. 2020-14-04-111].

\section{Footnote}

Reporting Checklist: The authors have completed the CONSORT reporting checklist. Available at https://dx.doi. org/10.21037/tp-20-370

Trial Protocol: Available at https://dx.doi.org/10.21037/tp20-370

Data Sharing Statement: Available at https://dx.doi. org/10.21037/tp-20-370

Conflicts of Interest: All authors have completed the ICMJE uniform disclosure form (available at https://dx.doi. org/10.21037/tp-20-370). The authors have no conflicts of interest to declare.

Ethical Statement: The authors are accountable for all aspects of the work in ensuring that questions related to the accuracy or integrity of any part of the work are appropriately investigated and resolved. The study was conducted in accordance with the Declaration of Helsinki (as revised in 2013). The study was approved by institutional ethics board of Kunming Children's Hospital (NO.: 201603-001-H01) informed consent was taken from the patients' parents or legal guardians.
Open Access Statement: This is an Open Access article distributed in accordance with the Creative Commons Attribution-NonCommercial-NoDerivs 4.0 International License (CC BY-NC-ND 4.0), which permits the noncommercial replication and distribution of the article with the strict proviso that no changes or edits are made and the original work is properly cited (including links to both the formal publication through the relevant DOI and the license). See: https://creativecommons.org/licenses/by-nc-nd/4.0/.

\section{References}

1. Li R, Cao X, Shi T, et al. Application of peripherally inserted central catheters in critically ill newborns experience from a neonatal intensive care unit. Medicine (Baltimore) 2019;98:e15837.

2. Erhard DM, Nguyen S, Guy KJ, et al. Dwell times and risk of non-elective removal of 1-French peripherally inserted central catheters according to catheter tip position in very preterm infants. Eur J Pediatr 2017;176:407-11.

3. Johnson KN, Thomas T, Grove J, et al. Insertion of peripherally inserted central catheters in neonates less than $1.5 \mathrm{~kg}$ using ultrasound guidance. Pediatr Surg Int 2016;32:1053-7.

4. Callejas A, Osiovich H, Ting JY. Use of peripherally inserted central catheters (PICC) via scalp veins in neonates. J Matern Fetal Neonatal Med 2016;29:3434-8.

5. Wang W, Zhao C, Ji Q, et al. Prevention of peripherally inserted central line-associated blood stream infections in very low-birth-weight infants by using a central line bundle guideline with a standard checklist: a case control study. BMC Pediatr 2015;15:69.

6. Baranowski ST, Hummler H, Hopfner RJ. Unusual malposition of a peripherally inserted central catheter (PICC) in a very low birth weight infant (VLBW Infant). Klin Padiatr 2014;226:248-9.

7. McCay AS, Elliott EC, Walden M. Videos in clinical medicine. PICC placement in the neonate. N Engl J Med 2014;370:e17.

8. Repa A, Mayerhofer M, Cardona F, et al. Safety of blood transfusions using 27 gauge neonatal PICC lines: an in vitro study on hemolysis. Klin Padiatr 2013;225:379-82.

9. Hammon RA, Seuss H, Hammon M, et al. Improved visualization of peripherally inserted central catheters on chest radiographs of neonates using fractional multiscale image processing. BMC Med Imaging 2019;19:3.

10. Tsai MH, Chu SM, Lien R, et al. Complications associated with 2 different types of percutaneously inserted central 
venous catheters in very low birth weight infants. Infect Control Hosp Epidemiol 2011;32:258-66.

11. Janes M, Kalyn A, Pinelli J, et al. A randomized trial comparing peripherally inserted central venous catheters and peripheral intravenous catheters in infants with very low birth weight. J Pediatr Surg 2000;35:1040-4.

12. Liu G, Hou W, Zhou C, et al. Meta-analysis of intracavitary electrocardiogram guidance for peripherally inserted central catheter placement. J Vasc Access 2019;20:577-82.

13. Ling Q, Chen H, Tang M, et al. Accuracy and Safety Study of Intracavitary Electrocardiographic Guidance for Peripherally Inserted Central Catheter Placement in Neonates. J Perinat Neonatal Nurs 2019;33:89-95.

14. Santacruz E, Mateo-Lobo R, Vega-Piñero B, et al. Intracavitary electrocardiogram (IC-ECG) guidance for peripherally inserted central catheter (PICC) placement. Nutr Hosp 2018;35:1005-8.

15. Zhou LJ, Xua HZ, Xu MF, et al. An Accuracy Study of the Intracavitary Electrocardiogram (IC-ECG) Guided

Cite this article as: Zhu LB, Liu L, Zhang TS, Zheng Y'T, Lu CY, Lu K, Zhang SX, Duan LY, Yang ML. A clinical study on the tip localization of peripherally inserted central catheter (PICC) guided by intracavitary electrocardiography in newborns: a randomised trial. Transl Pediatr 2021;10(10):24092417. doi: $10.21037 / \mathrm{tp}-20-370$
Peripherally Inserted Central Catheter Tip Placement among Neonates. Open Med (Wars) 2017;12:125-30.

16. Albertini F, Struglia M, Faraone V, et al. Effectiveness of the ECG method in the correct positioning of PICC type central venous catheters in patients with atrial fibrillation. Minerva Cardioangiol 2019;67:207-13.

17. Gao Y, Liu Y, Zhang H, et al. The safety and accuracy of ECG-guided PICC tip position verification applied in patients with atrial fibrillation. Ther Clin Risk Manag 2018;14:1075-81.

18. Elli S, Cannizzo L, Marini A, et al. Evaluation of tip location reliability of intraprocedural ECG vs. chest Xrays in PICC placement. Assist Inferm Ric 2016;35:174-9.

19. Rossetti F, Pittiruti M, Lamperti M, et al. The intracavitary ECG method for positioning the tip of central venous access devices in pediatric patients: results of an Italian multicenter study. J Vasc Access 2015;16:137-43.

20. Oliver G, Jones M. Evaluation of an electrocardiographbased PICC tip verification system. Br J Nurs 2013;22:S24-8. 


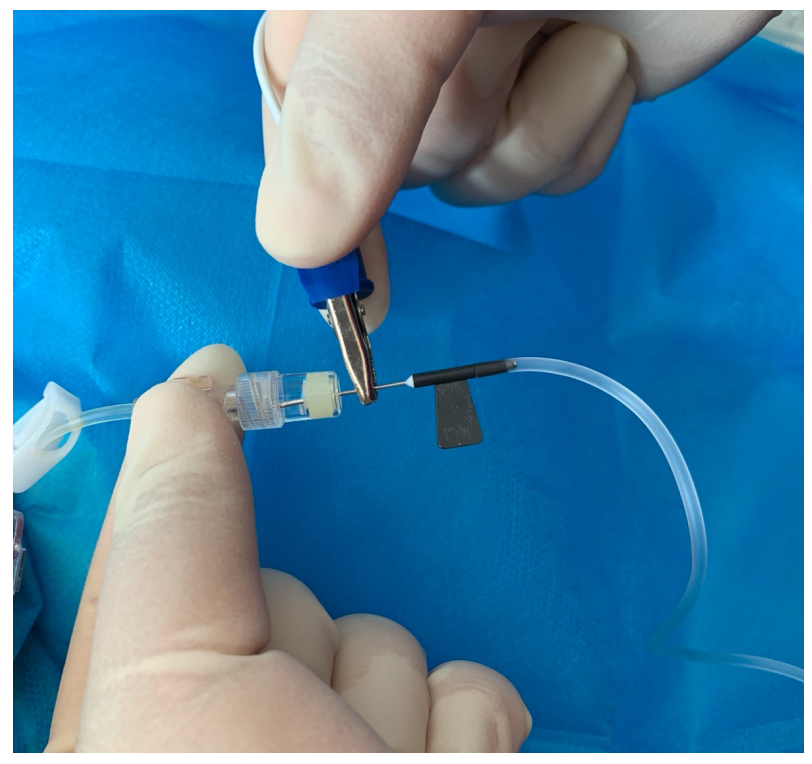

Figure S1 A photo of how the scalp needle was used through the cap and attached to the electrocardiogram. 